\title{
Delphi Method: The Development of Robotic Learning Survey in Tertiary Education
}

\author{
Irdayanti Mat Nashir ${ }^{1 *}$, Abdullah Yusoff², Moh Khairudin³, Muhammad Ridzuan \\ Idris ${ }^{4}$, Nurul Nazirah Imam Ma'arof ${ }^{1}$ \\ ${ }^{1}$ Universiti Pendidikan Sultan Idris, Tanjung Malim, Perak, Malaysia \\ 2Politeknik Sultan Azlan Shah, Behrang, Perak, Malaysia \\ ${ }^{3}$ Universitas Negeri Yogyakarta, Karangmalang, Yogyakarta, Indonesia \\ ${ }^{4}$ Politeknik Sultan Mizan Zainal Abidin, Dungun, Terengganu, Malaysia \\ *Corresponding author, e-mail: irdayanti@ftv.upsi.edu.my
}

\begin{abstract}
This article clarifies the development of instrument which is related with robotic based learning by using the Delphi methods. The Delphi method provides the chance for researchers to gather input from participants without demanding them to work face-to-face. Often, the process is used to find consensus among experts who have different opinions and observations. The Delphi method enables group problem-solving using an iterative process of problem definition, discussion, feedback, and revisions. This paper discussed the basics of the Delphi method, its application potential, the selection of expert panels and the means on how consensus can be reached among the participants and also the procedure to obtain the final criteria of robotic learning which is 67 from 188 initially.
\end{abstract}

Keywords: Delphi technique, Expert panels, Instruments, Robotic based learning, Robotic learning, Technical and vocational education.

\section{INTRODUCTION}

The achievement of a student is critical if there is no appropriate teaching and learning method that can attract students to learn the subject in the school. As educators are encouraged to find more appropriate ways to make teaching and learning interesting in the classroom. The teaching style is applied include blended learning and virtual learning, such as the use of Kahoot \& Quizzes in classroom. This study will discuss robotic-based learning in technical teaching and learning as an initial preparation in the field of Industry and Education challenges 4.0.

In addressing the challenges of Industry and Education 4.0, educational institutions in Malaysia are equally required to empower high technology-based teaching and learning in line with current industry needs and competent. Among the efforts undertaken was to inculcate the interest of students in the field of automation and robotics which became the core of the progress and development of Industry 4.0. Numerous programs involving robotics should be made so that students are given the opportunity to explore and implement innovative and creative research projects, thereby polishing the students' potential and talents in a systematic and good manner where students will use their creativity, knowledge and skills by creating and developing a product comprehensive and innovative. The Ministry of Education has also highlighted the Science, Technology, Engineering and Mathematics (STEM) program which stands for globally applicable STEM in education. In developing countries, many implementations are made to transform the traditional style of teaching and learning into a more active one in the classroom. In Malaysia, the majority of the classroom scenarios in school are still at the same level. Teacher stood up to teach in front, with the student sitting listening and writing what was said. However, various efforts have been made to change this situation by introducing various programs related to the latest teaching methods that have been implemented to complement the current education curriculum. 
There are various teaching methods that can be applied when dealing with students in the classroom, teachers also have a variety of approaches and methods that can be used in teaching and learning. However, the approach must be suitable for students as each student has a different background, character, ability and achievement. This is also agreed by Dommet (2018) which is a chosen approach and planned method may not be all suitable teaching and learning approaches to all students, but there are groups that fit the selected approach. Teacher skills using an approach are also different and depend on the type of learning theory supported (Shahabuddin \& Rohizani, 2007; Karim, Lemaignan \& Mondada, 2016). However, teachers need to explore each selected approach and method used, to apply the approach to the class in the classroom. Teachers can also diversity the teaching and learning approaches in the classroom to attract students to study the subject. Furthermore, there is no specific evidence that only one approach is the best and can solve all learning problems. Therefore, teachers need to adapt the approach used with the content of the lesson to be more effective and attractive in the classroom.

In this study, robotic-based learning was introduced to students in the classroom. One of the key features of this learning is that students become the major players in teaching and learning sessions. Students are encouraged to actively engage in each of these robotic learning sessions. More time is spent on students exploring and solving learning problems with the help of teachers acting as facilitators or mentors (Coon, Mitterer, \& Martini, 2018). The communication pattern used is also more active with interactions between teachers, students and robotics based learning materials. Teachers practice democratic leadership patterns and students are free to ask questions and give opinions. Teachers also encourage students to actively try and do their own learning activities. The achievement of the recorded learning objectives is the ultimate objective of this robotic-based learning. Many discussion techniques are conducted to foster co-operation and tolerance among students with a diverse range of abilities and interests.

\section{RESEARCH METHOD}

Robotic-based learning has initiated to be applied in the classroom but there are no specific criteria for identifying students' interest in robotic-based learning within the class. Therefore, this study will develop a checklist of robotic-based learning criteria using the Delphi technique.

\section{The Delphi Technique}

The Delphi Technique is represented here dependent on a past report directed by a gathering of analysts in specialized and professional instruction (TVE). The point of this specific investigation was to get criteria of mechanical based learning by utilizing the Delphi system. The reason for these criteria were to get premium understudy to the automated based learning. These criteria of robotic learning (RL) are significant in the endeavours to adjust the Malaysia instruction framework specifically and creating instructive associations by and large. What's to come is a clear space that isn't obscure to anybody however it's relied upon to be finished by us (Loo, 2002). Desires for future examination are one of the new procedures that enable us to outline the future course; and furthermore help strategy creators define an activity plan to not make the wrong suspicions about the conceivable outcomes that may happen later on. Creswell (2014) portrays the normal future objectives are to help the gatherings in a specific condition of recognition, options and decisions about what's to come. Likewise, Bogdan \& Bliken (2002) says future examinations illuminate the likelihood of the improvement of the ideal future. The view was additionally upheld by Linstone \& Turoff (1975), which portrays the future as "A feeling of things to come is behind

Mat Nasir, I., Yusoff, A., Khairudin, M., Idris, M. R., \& Ma'arof, N. N. I. (2019). Delphi Method: The Development of Robotic Learning Survey in Tertiary Education. Journal of Vocational Education Studies, 2(1), 13-22. DOI: https://doi.org/10.12928/joves.v2i1.761. 
every single great approach. Except if we have it, we can give nothing either insightful or not too bad to the world." The Delphi method advanced from work attempted by the RAND Corporation with the US military during the 1950s to acquire accord among a gathering of specialists by utilizing study and controlled input (Linstone \& Turoff, 1975). The method means to accomplish "organized correspondence" among such gatherings and has been connected in numerous and shifted circumstances running from looking at chronicled occasions, investigating arranging choices, assessing spending assignments, separating between different choices through to scholastic research (Keeney et al., 2001; Okoli \& Pawlowski, 2004) and educational modules advancement, principally in clinical showing regions (Linstone \& Turoff, 1975; Alahlafi \& Burge, 2005; Clibbens et al., 2012).

Linstone \& Turoff (1975) propose it is the idea of the gathering correspondence process instead of the issue being tended to that manages the suitability of the procedure; in this manner its shifted applications. They recommend the Delphi procedure might be proper in conditions where:

(1) The issue may profit by group abstract decisions;

(2) Those who need to add to the issue have no history of correspondence and additionally may have extremely differing foundations and ability;

(3) The blended scope of skill should be kept up to stay away from mastery by one gathering or potentially while overseeing coordination, for example;

(4) The number of specialists who should be included is unreasonably enormous for eye to eye discourse;

(5) Regular gatherings are not plausible because of time and cost requirements.

The Delphi structure may along these lines be fit in circumstances where there is a need to structure a gathering correspondence process so as to accomplish a specific targets. At last, the method intends to encourage bunch correspondence so agreement can be accomplished, enabling choices to be made and the undertaking to push ahead. The procedure itself can be actualized in various ways; anyway it by and large includes at least three stages (Linstone \& Turoff, 1975). In Phase 1, the issues is investigated and members can contribute data they think about pertinent. Stage 2 , includes achieving a comprehension of how the gathering sees the issues (for example regions of understanding and contradiction just as appraisal of significance, attractive quality, attainability, etc). Stage 3 isn't fundamental however can be incorporated if there is critical difference in Phase 2 that should be investigated, coaxing out reasons hidden the various perspectives. Stage 4 (or the last stage) includes bolstering back the collected perspectives and assessing the data assembled. Members might be assembled into various boards or single board can be utilized. Utilization of numerous boards with various ability, for example, in Delphi considers embraced by Helen \& Alan (2015) who utilized two master boards speaking to essential consideration medical attendants and different authorities and Clibbens et al. (2012) who had two master boards spoken to by enrolled medical attendants and wellbeing administrations clients, is valuable in creating thoughts reflecting alternate points of view and can take into account examination of thoughts produced between gatherings. Be that as it may, as we looked to get by and large accord between the various specialists, utilizing a solitary board was considered increasingly fitting.

Mat Nasir, I., Yusoff, A., Khairudin, M., Idris, M. R., \& Ma'arof, N. N. I. (2019). Delphi Method: The Development of Robotic Learning Survey in Tertiary Education. Journal of Vocational Education Studies, 2(1), 13-22. DOI: https://doi.org/10.12928/joves.v2i1.761. 


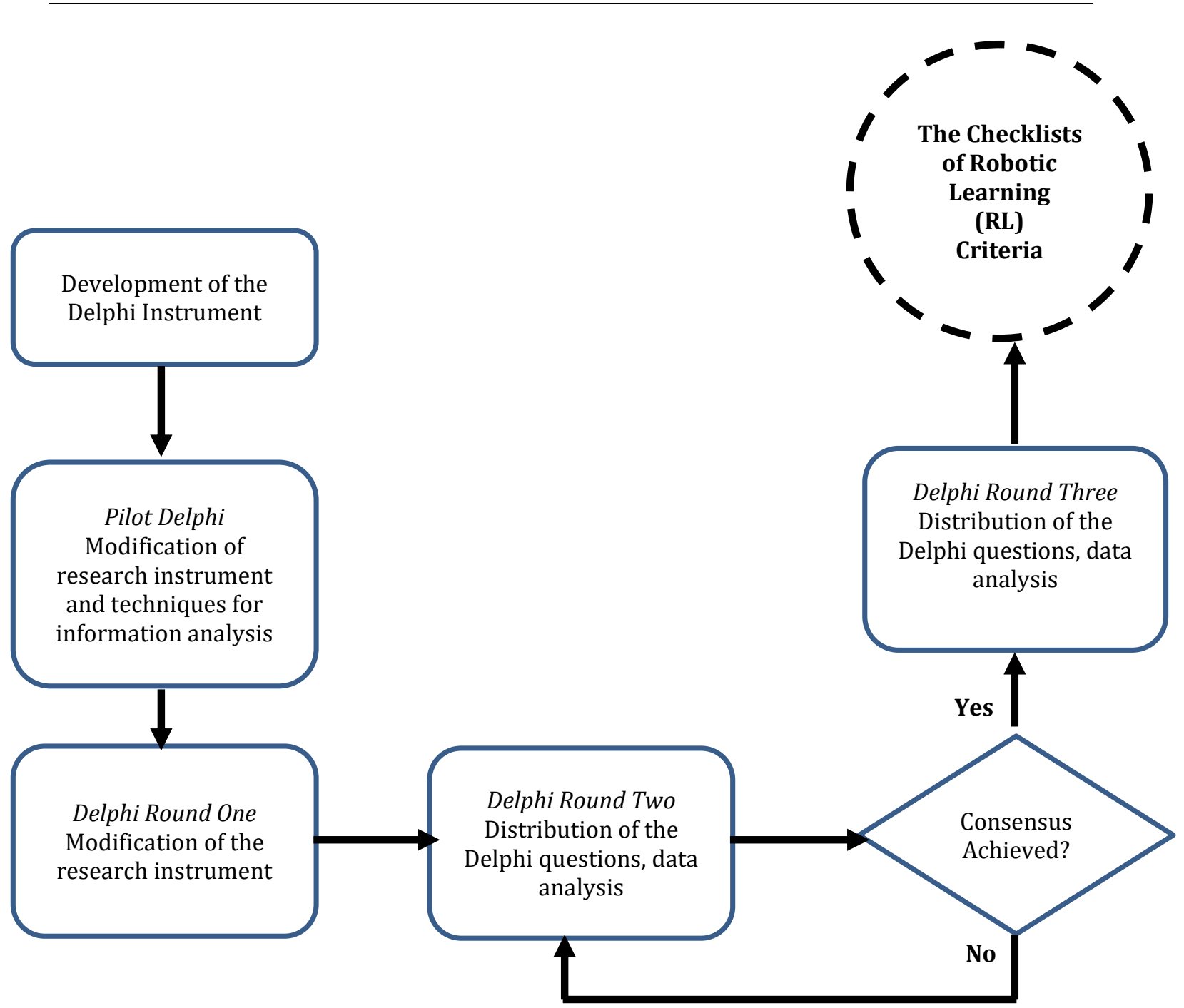

Figure 1. A typical three round Delphi method

\section{Development of the Delphi Survey}

Figure 1 show a typical of three round Delphi process involved in this research study. There are three Delphi rounds to identify criteria of robotic learning (RL) in the robotic teaching and learning.

\section{RESULTS AND DISCUSSION}

\section{Pilot of the Delphi}

In the flow inquire about, for a presentation measure to be held in a Delphi round, it should have been deciphered as either significant or significant in robotic learning (RL). Irrelevant execution measures in RL were not held. In the second and third adjusts, members were given the errand of rating the dimension of significance of the various exhibitions measures in RL. The rating depended on Table 1 with four-point Scale. Scales 1 and 2 ("very important" and "important") spoke to the positive class, while scales 3 and 4 ("unimportant" and "very unimportant") spoke to the negative classification. In this manner, the accompanying criteria were utilized to translate the exhibition measures.

Mat Nasir, I., Yusoff, A., Khairudin, M., Idris, M. R., \& Ma'arof, N. N. I. (2019). Delphi Method: The Development of Robotic Learning Survey in Tertiary Education. Journal of Vocational Education Studies, 2(1), 13-22. DOI: https://doi.org/10.12928/joves.v2i1.761. 
Table 1. The Point Scale of Rating the Level of Importance Criteria Measures in Robotic Learning

\begin{tabular}{ll}
\hline Scale & Percent \\
\hline Very important & at least 90 percent in the positive category \\
Important & 80 to 89 percent in the positive category \\
Unimportant & 70 to 79 percent in the positive category \\
Very unimportant & 69 percent or below in the positive category \\
\hline
\end{tabular}

Although a performance measure might be interpreted as very important or important, it was not immediately retained in a Delphi round. The Delphi participants needed to arrive at a consensus that the performance measure was important in robotic learning (RL). After the consensus achieved so that, the criteria of RL will go through to the next step the procedure of Delphi technique.

\section{Subsequent of the Delphi Rounds}

In some Delphi considers about Round 1 is a conceptualizing stage, where pros respond to open completed request while in various examinations individuals are drawn closer to respond to unequivocal proposals contained in a sorted out review. Concerning Critcher \& Gladstone (1998) note, in focusing the examination there is a levelling to be struck between making express proposals that individuals respond to and keeping a versatile inspiration to leave space for unconstrained duties from individuals.

Despite the fact that an underlying conceptualizing round is maybe perfect, since conceptualizing permits rises of numerous and differed thoughts (Brown \& Paulus, 2002), the hindrance of adopting this strategy is that it adds an extra round to the Delphi procedure. We needed to keep up cooperation levels and stay away from superfluous wearing down, so we picked to build up a wide scope of explicit recommendations for thought, since the writing gives a rich and changed scope of thoughts for incorporation in 21st century educational module. Moreover, a significant number of our scholastic specialists have added to 21st century writings and the scholarly discussion through their insightful productions and may have thought of us as poorly arranged on the off chance that we didn't exhibit our consciousness of the scholastic discussion in our field. We gave an open door in the first round for members to include any extra thoughts we had excluded. This we felt would conquer any potential loss of contribution because of the more organized study position.

For Round 1 based on the outcomes of pilot Delphi which is from the literature regarding key areas of robotic learning that "some people" might think are core areas in teaching and learning. Panelists were asked to indicate how important they felt each was using a point scale and to add any additional robotic learning they felt were important but had not been included in our initial lists.

In cycle 2 we nourished back the consequences of the Round 1 overview and solicited specialists to rate the significance from the extra things that had been proposed for consideration in the robotic learning (RL) zones. The study comprises of 188 things which depended on the discoveries from specialists in the first round of the development procedure of the RL criteria. In the second round, every master board was solicited to show their dimension from understanding, either unequivocally deviate, dissent, to some degree concur, concur and emphatically consent to the announcements introduced in the study.

Other than expressing their dimension of understanding, specialists were allowed the chance to include another things in the spaces gave if these things were esteemed applicable

Mat Nasir, I., Yusoff, A., Khairudin, M., Idris, M. R., \& Ma'arof, N. N. I. (2019). Delphi Method: The Development of Robotic Learning Survey in Tertiary Education. Journal of Vocational Education Studies, 2(1), 13-22. DOI: https://doi.org/10.12928/joves.v2i1.761. 
yet was not suggested in the first round of Delphi. The consequences of the second round of the review was broke down utilizing middle and bury quartile go (IQR). Range between quartiles (IQR) were utilized to depict the accord among specialists for everything whether high, moderate or no agreement and the middle (Median) for everything show the dimension of understanding Peck, Olsen, \& Devore (2015).

\begin{tabular}{|c|c|}
\hline High consensus & $=\mathrm{IQR} 0$ to 1.00 \\
\hline Moderate consensus & $=$ IQR 1.01 to 1.99 \\
\hline No consensus & $=\mathrm{IQR} 2.00$ and above \\
\hline High agreement & $=$ Median 4 to 5 \\
\hline Moderate agreement & $=$ Median 2.01 to 3.99 \\
\hline No agreement & $=$ Median 0 to 2 \\
\hline
\end{tabular}

For the final round, Round 3 we fed back the results of Round 2. This comprised rating of the additional robotic learning criteria and ranking of the items. We also provided panelists with a consolidated list of the 188 items they thought should be listed. Our Delphi process are typically run over a 12-13 week semester so it was essential to identify a viable amount of potential content to deliver in this timeframe. We also asked panellists to indicate their views on their experiences of the Delphi process.

Decision to stop the number of rounds was made when a high degree of consensus had been reached was consistent (Irdayanti et al., 2015). The panels have pointed out that it should be in between 2 to 10 rounds to get the best results that comply with the objectives of the study. However, the researcher also state that the number of rounds can be stopped after researchers have obtain enough information or if there is a preliminary agreement with a number of rounds the researchers need to conduct. Table 2 illustrates how the result was to be presented on the assessed indicator. Regarding to the Table 2, criteria of realistic, enterprising and conventional has been dropped because it has no consensus range. The final criteria of robotic learning is 67 from 188 criteria initially. In this procedure, when the agreement was high while the consensus is not reach, the researcher should consider with consensus rather than agreement (Irdayanti et al., 2015).

Table 2. Data Analysis for the Second to Three Round of Delphi Process

\begin{tabular}{|c|c|c|c|c|c|c|c|}
\hline \multirow[t]{2}{*}{ Criteria } & \multicolumn{3}{|c|}{ Second Round } & \multicolumn{3}{|c|}{ Third Round } & \multirow[b]{2}{*}{ Result } \\
\hline & Med & IQR & Consensus & Med & IQR & Consensus & \\
\hline Realistic & 4 & 2 & No & & - & & Dropped \\
\hline Investigate & 3 & 1 & High & 5 & 1 & High & Retained \\
\hline Artistic & 5 & 1 & High & 5 & 1 & High & Retained \\
\hline Social & 4 & 1 & High & 5 & 1 & High & Retained \\
\hline Enterprising & 4 & 2 & No & & . & & Dropped \\
\hline Conventional & 5 & 2 & No & & . & & Dropped \\
\hline
\end{tabular}

Med = Median, IQR =Inter Quartile Range

\section{Implications for Research}

Input from specialists about the barriers of our Delphi procedure with respect to a divided way to deal with educating and learning configuration recommends that a conceivably productive line of request is analyse how the aftereffects of the Delphi study can be joined into an instructing and learning configuration process for a solitary course.

Mat Nasir, I., Yusoff, A., Khairudin, M., Idris, M. R., \& Ma'arof, N. N. I. (2019). Delphi Method: The Development of Robotic Learning Survey in Tertiary Education. Journal of Vocational Education Studies, 2(1), 13-22. DOI: https://doi.org/10.12928/joves.v2i1.761. 
Like most earlier investigations that have utilized the Delphi system for instructing and learning configuration purposes (see, for example Fallon \& Trevitt, 2006; Witt \& Puntel de Almeida, 2008; Clibbens et al., 2012) our investigation concentrated on the established instructing and learning question about what information is of most worth for consideration in educating and learning Frieman (2016). Despite the fact that the course content is a key segment of an educational programs, the course fashioner likewise needs to settle on insightful decisions about a variety of other instructing and learning parts, including the course learning results, learning exercises and evaluations (Fink, 2003; Whetten, 2007). In a perfect world, these decisions ought to likewise be educated by scholarly and practice specialists. For instance, educating and learning authorities can give profitable direction on how the middle automated discovering that understudies ought to secure can be converted into a lot obviously learning results. Thus, the experts can aid the structure of working environment based appraisals that emphasis the understudies on applying their figuring out how to explicit settings and circumstances, and expect them to deliver real learning encounters and expertly significant reports that insert the learning background.

In this manner, a road for future research includes looking at how the Delphi strategy can be fused into a comprehensive arrangement of educating and learning configuration field ponders that are connected and at last lead to a well-structured instructing and learning. This could be accomplished by utilizing further Delphi forms, in which case the utilization of different master boards would empower agreement perspectives to be looked into bringing about improved wealth of substance and conveyance procedures. Another choice is lead interviews or to run little middle gatherings with nearby Delphi members subsequent to finishing the information accumulation stage. The reason for such meetings or middle gatherings is empower specialists to acquire point by point data that might be helpful for deciding the other educating and learning segments (for example showing methodology, appraisal techniques).

Given the input from expert specialists that the procedure encouraged reflection all alone practice, another region of future research is investigate through meetings how such reflection may impact their training. This could be survey regarding whether their desires while enrolling understudies would be increasingly practical just as any activities they would execute to framework the enlistment and early encounters accommodated understudies. Such meetings could be led not long after the Delphi consider or at interims to survey whether any foreseen changes coming about because of their appearance brought about changed practices over the long haul.

A last recommendation would be for the member reflection to be caught through phone or up close and personal meetings instead of the composed configuration utilized in our investigation. A solicitation in the last round for members to demonstrate their readiness to be met about the Delphi procedure experience would enable the scientists to get to members straightforwardly to increase further bits of knowledge into the member encounters and acquire proposals for upgrades that could improve the great practice rules.

\section{CONCLUSION}

This paper has introduced a case of utilized of the Delphi procedure for the criteria of automated based learning because of calls for increasingly contemporary and pertinent substance and educating systems. The choice to use this procedure was a reaction to the need to locate a powerful method to draw in a wide scope of specialists in recognizing the key of automated learning our understudies need to create amid their courses of study. Amid this examination, the scientist had distinguished a huge hole in the writing, not with

Mat Nasir, I., Yusoff, A., Khairudin, M., Idris, M. R., \& Ma'arof, N. N. I. (2019). Delphi Method: The Development of Robotic Learning Survey in Tertiary Education. Journal of Vocational Education Studies, 2(1), 13-22. DOI: https://doi.org/10.12928/joves.v2i1.761. 
respect to the utilization of the Delphi strategy but rather about the encounters of those associated with the procedure which could illuminate and improve utilization of the technique. So as to address the nonattendance of both member voice and analyst reflection on the functional utilization of the Delphi system we have displayed our examination of member criticism alongside our own encounters amid the procedure. Drawing on both our examination of the specialists criticism and our own appearance on the encounters of utilizing the Delphi system has empowered us to grow great practice rules for utilizing the Delphi procedure as an apparatus for educating and learning advancement. It is trusted that other instructing and learning engineers will receive these rules and that their encounters with the Delphi procedure will animate further dialog around great practice rules and increment the utilization of this system in future study hall plan. Also, the specialist recommended roads of further research give degree to grow both the writing and the pragmatic utilization of the Delphi strategy which have observed to be a beneficial instructing and learning advancement device, up to this point underutilized in business disciplines.

\section{REFERENCES}

Alahlafi, A., \& Burge, S. (2005). What should undergraduate medical students know about psoriasis? Involving patients in curriculum development: modified Delphi technique. British Medical Journal, 330(7492), 633-636.

Bogdan, R. C., \& Bliken, S. (2002). Qualitative Research in Education: An Introduction to the Theory and Methods (4th Ed.). Boston: Allyn Bacon.

Brown, V. R., \& Paulus, P. B. (2002). Making group brainstorming more effective: recommendations from an associative memory perspective. Current Directions in Psychological Science, 11(6), 208-212.

Clibbens, N., Walters, S., \& Baird, W. (2012). Delphi research: issues raised by a pilot study. Nurse Researcher, 19(2), 37-44.

Critcher, C., \& Gladstone, B. (1998), Utilizing the Delphi technique in policy discussion: a case study of a privatized utility in Britain. Public Administration, 76(3), 431-449.

Creswell, J. W. (2014). Research Design: Qualitative, Quantitative and Mixed Methods Approaches. Thousand Oaks: Sage Publications.

Coon, D., Mitterer, J. O., \& Martini, T. (2018). Psychology Modules for Active Learning. Boston: Cengage Learning.

Dommett, E. J. (2018). Learner ownership of technology-enhanced learning. Interactive Technology and Smart Education, 15(1). DOI: https://doi.org/10.1108/ITSE-082017-0042.

Fallon, K. E., \& Trevitt, A. C. (2006). Optimising a curriculum for clinical haematology and biochemistry in sports medicine: a Delphi approach. British Journal of Sports Medicine, 40(2), 139-144.

Fink, L. D. (2003). Creating Significant Learning Experiences. San Francisco: Jossey-Bass.

Frieman, J. S. R. (2016). Learning:A Behavioral, Cognitive and Evolutionary Synthesis (Reid Hester, Ed.). London: Sage Publications.

Helen, S., \& Alan, C. (2015). Using the Delphi technique to support curriculum development. Education + Training, 57(3), 306-321. DOI: https://doi.org/10.1108/ET-02-20140010.

Mat Nasir, I., Yusoff, A., Khairudin, M., Idris, M. R., \& Ma'arof, N. N. I. (2019). Delphi Method: The Development of Robotic Learning Survey in Tertiary Education. Journal of Vocational Education Studies, 2(1), 13-22. DOI: https://doi.org/10.12928/joves.v2i1.761. 
Irdayanti, M. N., Ramlee, M., \& Abdullah, Y. (2015). Delphi Technique: Enhancing Research in Technical and Vocational Education. International Business, 3, 34.

Karim, M. E, Lemaignan, S., \& Mondada, F. (2016), A review: Can robots reshape K-12 STEM education? 2015 IEEE International Workshop on Advanced Robotics and its Social Impacts (ARSO), 1-8. DOI: 10.1109/ARSO.2015.7428217.

Keeney, S., Hasson, F., \& McKenna, H. P. (2001). A critical review of the Delphi technique as a research methodology for nursing. International Journal of Nursing Studies, 38(2), 195-200.

Linstone, H. A., \& Turoff, M. (1975). The Delphi Method: Techniques and Applications. London: Addison-Wesley.

Loo, R. (2002). The Delphi method: a powerful tool for strategic management. Policing: An International Journal of Police Strategies \& Management, 25(4), 762-769.

Okoli, C., \& Pawlowski, S. (2004). The Delphi method as a research tool: an example, design considerations and applications. Information \& Management, 42(1), 15-29.

Peck, R., Olsen, C. \& Devore, J. L. (2015). Introduction to Statistics and Data Analysis (Brooks Cole, Ed.) (5th Ed.). Cengage Learning.

Shahabuddin, H. \& Rohizani, Y. (2007). Pedagogi: Strategi dan Teknik Mengajar dengan Berkesan. Kuala Lumpur: PTS Publications.

Whetten, D. A. (2007). Principles of effective course design: What I wish I had known about learner-cantered teaching 30 years ago. Journal of Management Education, 31(3), 339357.

Witt, R. R., \& Puntel de Almeida, M. C. (2008). Identification of nurses' competencies in primary health care through a Delphi study in Southern Brazil. Public Health Nursing, 25(4), 336-343.

Mat Nasir, I., Yusoff, A., Khairudin, M., Idris, M. R., \& Ma'arof, N. N. I. (2019). Delphi Method: The Development of Robotic Learning Survey in Tertiary Education. Journal of Vocational Education Studies, 2(1), 13-22. DOI: https://doi.org/10.12928/joves.v2i1.761. 
Mat Nasir, I., Yusoff, A., Khairudin, M., Idris, M. R., \& Ma'arof, N. N. I. (2019). Delphi Method: The Development of Robotic Learning Survey in Tertiary Education. Journal of Vocational Education Studies, 2(1), 13-22. DOI: https://doi.org/10.12928/joves.v2i1.761. 